\title{
Regional Variations of Infant Mortality in Kenya: Evidence from 2009 KDHS Data
}

\section{Joseph Misati Akuma}

\author{
LAM, Universite De Pau et Des Pays de l'Adour, France \\ Email: josephmisati at yahoo.com
}

\section{Doi:10.5901/mjss.2013.v4n9p425}

\begin{abstract}
High infant mortality rates remain a great challenge to the Kenyan Government as she strives to attain the Millenium Development Goals (MDGs). In its current Development Blue - Print, Vision 2030, the country aims at eliminating high poverty levels and reduce the high regional inequalities. This comparative paper focuses on the determinants of infant mortality in Kenya. It specifically examines the regional differences in infant mortality among the various regions in the country classified into two broad categories as High mortality and Low mortality regions respectively. Data used was derived from birth histories in the Kenya Demographic and Health Survey (KDHS, 2009). The findings of the study indicate that regional differences in under- one mortality are quite significant. The results show that low educational attainment, low socio - economic status and short intervals between births lead to the observed higher levels of infant mortality in the high mortality region. It is concluded that the regional differences in infant mortality are a result of the differences in the level of economic and social development. It is recommended that the Government implement policies aimed at increasing the length of birth intervals and improving the womens' financial and occupational status. Lastly, free secondary education will go along way in improving the welfare of womenfolk especially in the high mortality region.
\end{abstract}

Keywords: Infant Mortality Rate, Socio-economic factors, Vision 2030, Kenya

\section{Introduction and background}

Infant mortality remains a problem of concern in many parts of the world. In developing nations, high levels of infant deaths are recognized as problems warranting serious attention. In Kenya, although, major improvements have been achieved with Infant Mortality Rates reducing from 120 per 1000 deaths in 1963 to 62.5 per 1000 in 1993, It is estimated that 1 in every 19 children die before celebrating their first birthday (Republic of Kenya, 2009). Neo-Natal Mortality is 32 deaths per 1,000 live births, while Post Neo-Natal Mortality is 21 per 1,000 live births thus, 60 percent of infant deaths in Kenya occur during the first month of life (KDHS, 2009).

Available evidence indicates that there exists great regional variations in infant mortality, with certain regions inhabited by particular ethnic groups having higher infant mortality levels than others. The regions of high mortality are Nyanza and Western provinces adjacent to Lake Victoria and the coast province along the Indian Ocean inhabited by the Luo, Luyhia and Mijikenda respectively, but the challenges of improved survival of babies is most acute in Nyanza with a record infant mortality rate of 95 per 1,000 live births (Misati, 2011). On the other hand, Central province has the lowest infant mortality with lower levels observed in the adjacent Rift -Valley and Nairobi provinces (NCPD et al, 2009). At district level, Homabay district has more than 200 infants dying before their first birth day while Nyeri had 52 . According to KDHS 2009, Infant mortality rate increased from 66 to 68 per 1,000 live births between 1979- 1989 and 1989- 1999 and 1999- 2009 inter - Censal period (Republic of Kenya, 2002; Republic of Kenya, 2009). The increases present serious policy implications when considered against the goals and targets set out by the Millennium Development Goals (MDGS).

In order to address the afore - mentioned gloomy mortality situation there is need to reduce poverty levels currently experienced in order to increase the proportion of people with access to quality health care services and minimize the current regional disparities in mortality.

\section{Determinants of Infant Mortality}

In Kenya studies have shown that infant mortality varies according to socio- economic variables such as maternal factors, exposure to diseases and use of modern health services (Ikamari, 1996). The said socio- economic factors have been seen to influence infant survival through "a complex web of pathways" in which case access to and use of health 
facilities and piped water are some of the mediating factors for majority of the socio- economic determinants. At the community level, it has been established that in communities where malaria is not endemic, and immunization coverage exceeds $67 \%$ have statistically significant negative association with the risk of infant death. In addition, better toilet facilities, better quality housing floor materials and less contaminated water have been found to have statistically significant negative association with infant death (Koyugi, 1986).

Studies by Hobcraft, McDonald and Rustein (1984) and Mosley (1984) shows that in Kenya, the increase infant mortality associated with a low level of maternal education is greater in the poor regions of the country. On their part, economists have tended to stress the notion that maternal education operates through the allocation of material time to market and non- market activities. By enhancing women's potential returns from work, increased education can stimulate labor force participation. In return, the working mother has less time to devote to child care but increase the family's economic resources, which might have a favorable impact on child health.

Using districts level data, Kibet (1981) sought to investigate factors influencing Infant Mortality at the macro-level. He found out that there existed a significant correlation between infant mortality and education. The study concluded that the variations in different mortality levels among districts in Kenya were partly as a result of the existing educational differentials among the districts. However, in his study on the "impacts of household and community level environmental factors on infant and child mortality in rural Kenyan", K'oyugi (1992) observed that maternal education of under nine years had insignicant protective effects on infant mortality. Harrington's (1974) study of West African societies view an infant's chances of survival as the outcome of a series of factors governing exposure to diseases and those encompassing the course and outcomes of diseases among them, he observes, is the type of dwellings which mainly affects mortality through the elements of exposure. In Sudan, living in a house made from mud raises the infant's mortality by a statistically significant $6 \%$ in the capital and $7 \%$ at the national level (Farah and Preston, 1982).

\subsection{Study Conceptual framework}

This study is based on the premise that, although the ultimate cause of death is biological, the determinants of the fatal Biological factors may be a chain of socio-cultural, economic, demographic and environmental factors. The conceptual framework, therefore, is adopted from that proposed by Mosley and Chen (1984:25)

Figure 1: Operation of the Proximate Determinants on the Health Dynamics of a Population.

\section{Study Conceptual Framework}

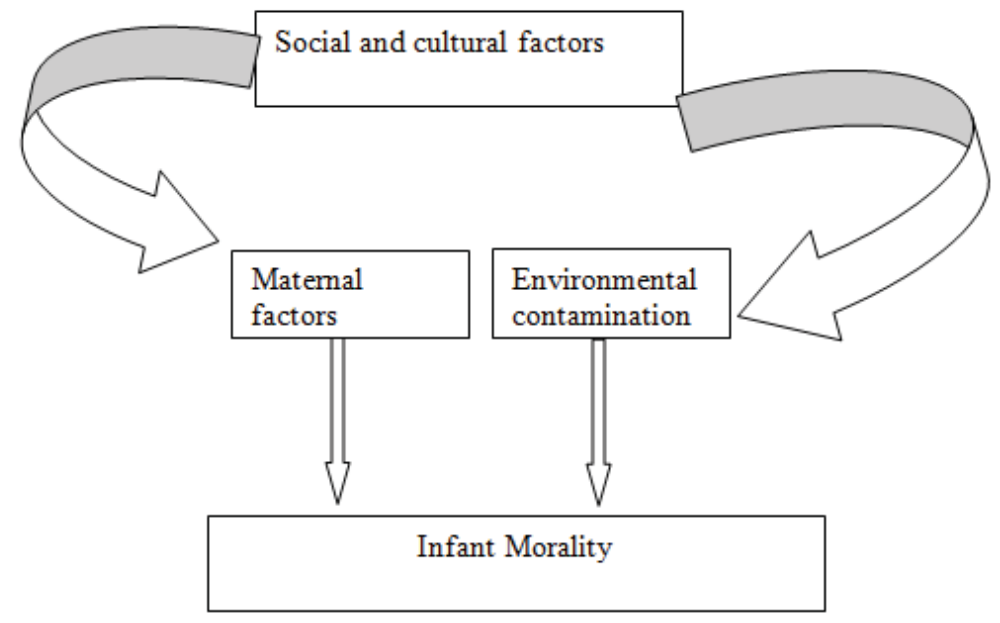

Source: Adopted from Mosley and Chen (1984:25) with slight modification to suit purpose of the study. 


\subsection{Operational definition of variables and concepts}

a) Infant mortality - Is the death that occur to children who are born alive between the time of birth and level not yet celebrated their first birth day ( 0 -11 Months)

b) Low mortality region- Refers to the three provinces namely Central, Nairobi and Rift- valley which recorded the lowest infant and child mortality rates in the $2009 \mathrm{KDHS}$.

c) High mortality region - Refers to the two provinces which recorded the highest infant and child mortality rates in the 2009 KDHS. They are Nyanza and Western and Coast.

d) Maternal education level - The highest level of formal schooling attained by the mother. It is categorized into; No - education, Primary education,

e) Mothers religious affiliations- Refers to whether a woman belongs to protestant and other Christians, Catholic, Muslim or others. This is a cultural variable which helps in measuring the beliefs and attitudes towards family size and health seeking behavior that directly impact on child health and hence survival.

f) Ethnicity - Refers to the ethnic group tribe the mother belongs to i.e. whether Luo. Kikuyu. Kalenjin etc. It measures beliefs and cultural practices that impacts on child health and survival.

g) Mothers' occupation - The variable refers to work status category of the mother at the time of the survey. The categories include: Not working, Professional. Self-employed /domestic work or manual.

h) Maternal age - Exact age of the mother at the time of the survey. The variable is categorized into three categories. Those aged less 19 years, 20-34 years and those aged 35 years and above.

i) Preceeding birth interval - Time in months that elapsed between the index child and another birth. It is categorized into; less 14 months, 15-19 months and above 20 months.

j) Type of housing floor material - A variable indicating the main materials used for constructing the floor of the house. It is categorized into cement, mud/dung /sand and others.

k) Source of drinking water - The main source of water for use in the household. It's used as a proxy to indicate the conditions bearing on disease causing agents at the household level. It is categorized into; piped, well, river /stream /lake, rain and others.

I) Type of toilet facility - Type of facility used to dispose human waste. Like water source and floor materials, the variable is meant to capture disease causing agents and a proxy for economic status of the household. It is categorized into whether a household uses a pit latrine, flush toilet or the bush.

$\mathrm{m}$ ) Mothers' age at first birth -- Refers to the age in years of the mother at the time her first birth occurred.

\section{Materials and Methods}

\subsection{Data Source}

The study data was drawn from the Kenya demographic and health survey (KDHS, 2009).The KDHS is a nationally representative sample of 8444 women aged $15-49$ and their children. Data collection took place over a three month period, from 13 $3^{\text {th }}$ November, 2008 to late February, 2009.

\subsection{Study Design and Sampling}

The Demographic Health Survey utilized a two-stage sample design. The first stage involved selecting sample points (clusters) from a national master-sample maintained by the Kenya National Bureau of Statistics (KNBS) -NASSEP IV.

\subsection{Data analysis}

Cross tabulation was used to determine the relationship between independent variables and infant death. It was preferred for this study due to its appropriateness in comparative analysis and because could clearly illustrate the distribution and relationships referred to above according to each category of the selected variable in the mortality regions. The chi - square statistic was used to test the association between two variables in the cross - tabulation tables. The alpha level selected is 0.05 . In any observed significance which was less than the Alpha, it was concluded that there is an association between the dependence and independent variables, while that larger than the alpha value of 0.05 was taken as indicating no association between the variables. In order to assess the effects of the various factors on the risk 
of infant death, logistics regression analysis was applied. It was used in the study to estimate the likelihood of survival for infants given the prevailing socio-economic, demographic and environmental situation in the mortality regions. The logistic regression model is shown as:-

$$
p[x]=\frac{e^{B 0}+{ }^{B 1 X}}{1-^{B 0}+{ }^{B 1 X}}
$$

Where,

$\mathrm{P}(\mathrm{x})$ is = Probability of Infant Death

e $\quad=$ Base of the natural logarithm, to $2.71828 \ldots$

$B_{o} \& B_{1}=$ Coefficients estimated from the data

$\mathrm{x}=$ Dependent variables

A model involving all the independent variables and infant death was run. To create the dependent variables, i.e. Infant death, 60 months were subtracted from the date of the interview (child morality) and the resulting period was divided into (0-11) months to represent infant death. In order to increase the number of cases a ten year observation period was created by subtracting 120 months from the date of the interview.

\subsection{Recoding of variables}

It became necessary to combine mothers who had attained "secondary level of education" and those of "tertiary" category due to the relatively small number of mothers in the latter group in both regions of study, hence coming up with three broad categories of "None", "Primary" and "Secondary". Similarly Mothers' occupation was grouped into four categories; maternal age into three categories, preceding birth intervals and maternal age at first birth were also transformed into three categories. Source of drinking water supply and Mothers' religious affiliation were classified into four categories. The regions (provinces) were recoded into two categories, namely; High Mortality Region (HMR) and Low Mortality Region (LMR).

\section{Results}

\subsection{The study Sample}

The study population consists of a sub - sample of 8061 births. The births took place between 1998 and 2009 among women aged 15- 49. Of all births, $44.4 \%$ occurred to women who were either self- employed or engaged in domestic work in the high mortality region and $35.1 \%$ in the low mortality region. Distribution by maternal age indicates that the largest number of births were recorded among women aged 20-34 in both regions, a finding which conforms to expectation as the age - bracket of 20-34 is regarded as the prime age for child bearing among women. By maternal education level, it is shown that more than half of the births ( $64.5 \%$ and $64.6 \%$ respectively) occurred to women who had attained primary education level in both regions, while those born to women who had attained secondary level education and above constituted $24.1 \%$ and $23.5 \%$ in the high and low mortality regions respectively. The study indicated that in the high mortality region, $60 \%$ of the births occurred to women whose main source of drinking water was either a river, a stream or lake while those in the low mortality region were $4.2 \%$ of the total births. Lastly, the results indicated that $8 \%, 20.3 \% 71.7 \% 59 \%$ and $41 \%$ of the births occurred to women who hailed from Nairobi, Central, Rift valley, Nyanza and western provinces in that order.

\subsection{Infant mortality differences in the mortality region}

Table.1 shows the infant mortality differentials in the mortality regions. The results indicate that in the High mortality region the lowest infant deaths were recorded among the mothers who are classified as "professionals". It is similarly observed that in the high mortality region, the mortality rates are twice compared with those observed in the low mortality region among the professional category. By maternal age, it is observed that in both regions, the highest death rates are recorded among infants whose mothers are aged35 years and above. In both regions, the highest number of deaths are observed among infants belonging to women with "No education", while the lowest rates are observed among women categorized as having attained "Secondary and above "level of education. In both regions, children born within an interval of 14 months and below experienced the greatest infant mortality rates. By maternal education in both the high and low 
mortality regions, the greatest deaths occurred to infants born among women who had received "No education"

Table 1. Infant mortality differentials in the mortality regions.

\begin{tabular}{|c|c|c|}
\hline \multirow{2}{*}{\multicolumn{3}{|c|}{$\begin{array}{l}\text { Variable } \\
\text { Mother occupation }\end{array}$}} \\
\hline & & \\
\hline Not working & 38.4 & 7.9 \\
\hline Professional & 6.2 & 13.8 \\
\hline Self-employed/domestic & 48.5 & 13.9 \\
\hline Manual & 36.0 & 42.9 \\
\hline \multicolumn{3}{|l|}{ Maternal age } \\
\hline$<19$ & 45.5 & 13.1 \\
\hline $20-34$ & 45.9 & 12.5 \\
\hline $35+$ & 53.5 & 12.8 \\
\hline \multicolumn{3}{|l|}{ Preceding birth intervals } \\
\hline$<14$ & 34.3 & 29.4 \\
\hline $15-19$ & 8.7 & 13.2 \\
\hline $20+$ & 4.5 & 15.9 \\
\hline \multicolumn{3}{|l|}{ Maternal education } \\
\hline No education & 70 & 16.1 \\
\hline Primary & 52.3 & 13.2 \\
\hline Secondary & 27.0 & 15.9 \\
\hline \multicolumn{3}{|l|}{ Source of drinking water } \\
\hline Piped & 36.2 & 16.0 \\
\hline Well & 46.6 & 8.3 \\
\hline River/stream/lake & 52.1 & 11.0 \\
\hline Rain/other & 30.7 & 15.5 \\
\hline \multicolumn{3}{|l|}{ Main floor material } \\
\hline Cement & 36.1 & 14.2 \\
\hline Mud/dung/Sand & 50.8 & 11.4 \\
\hline Other & - & \\
\hline \multicolumn{3}{|l|}{ Type of toilet facility } \\
\hline Flush & 37.4 & 8.7 \\
\hline Pit latrine & 44.7 & 10.0 \\
\hline Bush/Other & 66.7 & 23.8 \\
\hline \multicolumn{3}{|l|}{ Religion } \\
\hline Catholic & 54.9 & 1.0 \\
\hline Protestant /Other Christian & 46.7 & 1.2 \\
\hline Muslim & 1.0 & 1.0 \\
\hline Other & 1.0 & 1.4 \\
\hline \multicolumn{3}{|l|}{ Mothers age at first birth } \\
\hline$<17$ & 60.4 & 19.1 \\
\hline $18-23$ & 39.1 & 1.5 \\
\hline $24+$ & 35.5 & 5.0 \\
\hline \multicolumn{3}{|l|}{ Ethnicity } \\
\hline Kalenjin & 1.3 & 4.3 \\
\hline Kamba & 1.0 & 1.0 \\
\hline Kikuyu & 1.0 & 1.0 \\
\hline Kisii & 2.8 & 6.9 \\
\hline Luhyia & 1.4 & 4.6 \\
\hline Luo & 4.5 & 1.2 \\
\hline Masaai & 1.1 & 1.3 \\
\hline Others & 1.7 & 1.0 \\
\hline
\end{tabular}

Source: Analysis of the Kenya National Bureau of Statistics, KDHS 2009 Data. 


\subsection{Regional variations of infant deaths in Kenya.}

Results of Multivariate logistic regression analysis in table. 2 shows that the "Mothers' occupation" has a significant effect on the risk of infant death in the low mortality region while it shows no significant effect on Infant death to the high mortality region. It is specifically noted that the greatest increases are by the "manual" and "self - employed /domestic" categories in the low and high mortality regions respectively. On preceding birth intervals, the results show that its effects is only significant in the High Mortality region. Turning to the type of toilet facility and maternal age, the results shows that the two variables have no significant effect on Infant death in both regions.

Maternal education was seen to have a significant effect in the High mortality region. On the other hand maternal education level was found not to be significantly associated with the risk of infant death in the low mortality region. In both regions, "Mothers' education level" shows a reducing effect on infant death. Infants born of parents with a "primary education" level have a lower probability of dying compared to those whose mothers have attained 'no education'.

Contrary to what was hypothesized, the results indicate that source of drinking water, main floor material, mothers' religious affiliation and ethnicity are not significantly associated with the risk of infant death in both regions. However, in the HMR, it is evident with reference to the reference category (Kikuyu), being born of parents of Luo and Luyhia origin shows the highest increases in the odds of death at infancy.

Table2. Results of Multivariate logistic regression analysis showing the effects of independent variables on the risk of infant death in the low and high mortality regions.

\begin{tabular}{|c|c|c|c|c|c|c|c|c|c|c|}
\hline & \multicolumn{5}{|c|}{ Low mortality region } & \multicolumn{5}{|c|}{ High mortality region } \\
\hline Variable & B & S.E & D.f & Sig & Exp & B & S.E & D.f & Sig & Exp \\
\hline \begin{tabular}{|l|} 
1) Occupation \\
Not working (R.C)
\end{tabular} & 0.00 & & & & 1.00 & 0.00 & & & & 1.00 \\
\hline Professional & 1628 & .5473 & 1 & .7661 & 1.1768 & 1711 & .6541 & 1 & .7936 & 1.1866 \\
\hline Self employed domestic & 2811 & .4002 & 1 & .4824 & 1.3246 & .7241 & .6332 & 1 & .2528 & 2.0628 \\
\hline Manual & 1.5795 & .5750 & 1 & .0060 & 4.8526 & .2943 & .2943 & 1 & 6414 & 1.3422 \\
\hline $\begin{array}{l}\text { 2) Preceding birth interval } \\
<14\end{array}$ & -.3396 & .6900 & 1 & .6226 & .7121 & -.1907 & .4310 & 1 & .6582 & .8264 \\
\hline $\begin{array}{l}15-19 \\
20-(\text { R.C) }\end{array}$ & $\begin{array}{c}-.7011 \\
0.00\end{array}$ & .5020 & 1 & 1625 & .4960 & $\begin{array}{l}.7430 \\
0.00\end{array}$ & .2382 & 1 & $.0019^{*}$ & 2.0981 \\
\hline 3) Material age & & & & & & & & & & \\
\hline$<19$ & .7324 & & & & 2.0801 & -5.6131 & .9992 & 1 & .6885 & .0036 \\
\hline $20+34$ & 0137 & .6922 & 1 & .0176 & 1.0138 & -.1665 & .1925 & 1 & .3869 & .8466 \\
\hline $35+$ (R.C) & 0.00 & .6927 & 1 & $.0191^{\star \star}$ & 1.00 & $0 . .00$ & & & & \\
\hline ilet facility & & & & & & & & & & \\
\hline $\begin{array}{l}\text { Flush (R.C) } \\
\text { Pit }\end{array}$ & $\begin{array}{l}0.00 \\
.9840\end{array}$ & .0820 & 1 & .3632 & $\begin{array}{c}1.00 \\
2.6750\end{array}$ & $\begin{array}{c}0.00 \\
1.0167\end{array}$ & 7232 & 1 & .1597 & $\begin{array}{c}1.00 \\
2.76375\end{array}$ \\
\hline Bush/Others & 1.861 & .1556 & 1 & .1181 & 6.0866 & .0059 & .2356 & 1 & .9799 & .06155 \\
\hline $\begin{array}{l}\text { 5) Maternal education } \\
\text { No education (R.C) }\end{array}$ & & & & & & 0.00 & & & & 1.00 \\
\hline Primary & 0.00 & & & .6572 & 1.00 & -8267 & .3359 & 1 & $.0138^{*}$ & 04375 \\
\hline Secondary & -.2035 & 4586 & 1 & & 8158 & -.4853 & 2799 & 1 & $.0829^{*}$ & 6155 \\
\hline 6)Source & & & & & & & & & & \\
\hline Piped (R.C) & 0.00 & & & & 1.00 & 0.00 & & & & 1.00 \\
\hline Well & 6868 & .5132 & 1 & .1808 & .5032 & 2175 & .0795 & 1 & .8403 & 1.2430 \\
\hline River/Streams/lakes & 4839 & .4636 & 1 & .2966 & .6164 & 4875 & .0469 & 1 & .6415 & 1.6282 \\
\hline Rain/ Others & .2250 & .740 & 1 & .8341 & .7986 & 6176 & .0400 & 1 & .5526 & 1.8545 \\
\hline $\begin{array}{l}\text { 7) Main floor material } \\
\text { Cement (R.C) }\end{array}$ & 0.00 & & & & 1.00 & 0.0 & & & & 1.00 \\
\hline Mud/Dung/Sand & .1494 & .4544 & 1 & .7424 & 1.1610 & .5681 & .5612 & 1 & .7827 & 3579 \\
\hline Others & -6.3622 & .2260 & 1 & .8083 & .0017 & 9870 & .5594 & 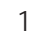 & .7633 & 4925 \\
\hline $\begin{array}{l}\text { 8) Religion } \\
\text { Catholic( R.C) }\end{array}$ & 0.00 & & & & 1.00 & 0.00 & & & & \\
\hline Protestant/Other Christian & .3746 & .3952 & 1 & .3432 & 1.4545 & .2660 & .0695 & 1 & .8036 & 1.00 \\
\hline Muslim & -6.4383 & 6991 & 1 & .8948 & .0016 & -.0022 & .0618 & 1 & .9984 & 9979 \\
\hline
\end{tabular}




\begin{tabular}{|l|c|c|c|c|c|c|c|c|c|c|}
\hline Others & -4.6303 & .4861 & 1 & .9141 & .0098 & -4.9997 & .7265 & 1 & .6698 & .0064 \\
\hline 9$)$ Mother's age at first birth & & & & & & & & & & \\
$<17$ & -.3443 & & & & .7087 & .4069 & & & & 1.5022 \\
$18-25$ & -.9788 & .3565 & 1 & .3342 & .0009 & .1582 & .5433 & 1 & .4539 & 1.1714 \\
$24+($ R.C) & 0.00 & .1165 & 1 & .6650 & 1.00 & 0.00 & .5365 & 1 & .7693 & 1.00 \\
\hline 10) Ethnicity & & & & & & & & & & \\
Kalenjin (R.C) & 0.00 & & & & 1.00 & & & & & 1.00 \\
Kamba & .9624 & .0989 & 1 & .3811 & 2.6181 & & & & & 1.666 \\
Kikuyu & -.0456 & .5085 & 1 & .9286 & .9554 & & & & & 0.0175 \\
Kisii & 06.3967 & .0102 & 1 & .8365 & .0017 & & & & & 0.0008 \\
Luhya & .7258 & .5303 & 1 & .1711 & 2.0664 & & & & & 1.7378 \\
Luo & 1.3329 & .6543 & 1 & $.0416^{\star *}$ & 3.7921 & & & & & 1.3694 \\
Maasai & -4.9667 & .3923 & 1 & .9770 & .0070 & & & & & 0.037 \\
Others & -6.3348 & .0696 & 1 & .8525 & .0018 & & & & & 1.3963 \\
\hline \multicolumn{1}{|l|}{ R.C-Ren } \\
\hline
\end{tabular}

R.C - Reference Category, ${ }^{* * *}<0.01,{ }^{* *} p<0.05, \quad{ }^{*} p<0.1$

Source: Analysis of the Kenya National Bureau of Statistics KDHS, 2009 Data.

\section{Discussion}

The survival of infants at birth and the subsequent months depends in a number of Socio- economic, Environmental and Cultural factors. Several researchers using data from African countries have established that educational attainment of parents is inversely related to infant mortality (Caldwell, 1979; Anker and Knowles, 1977 and Mott, 1982). The inverse association is attributed to various causes, including: Breakdown of unfavorable traditional child rearing practices, Better nutrition knowledge, Increased amount of income and redistribution of family resources in favour of children. Mosley (1983) argues that the geographical differences in infant mortality could be explained by education and nutrition as a result of levels of economic and social development. Palloni (1991) study which underscores the importance of social circumstances in which the mother lives, concluded that in poorer settings, the uneducated mothers were at far greater disadvantage with respect to survival chances of their infants compared to the more educated. Palloni's finding was noted to apply to Kenya's situation in 1979 when estimates of infant mortality rates by mothers education for districts in Kenya revealed that women with secondary education in poorer districts of South Nyanza reported a lower mortality compared to the uneducated women in the same district, but when this rate for the secondary educated women was compared to the rate for the uneducated women in a better of Nyeri district, the uneducated mothers in Nyeri had a lower infant mortality than the secondary mothers in South Nyanza district (Kibet, 1981).

Other Socio - economic factors influencing circumstances in household are mothers' occupation and geographic area of residence. Culture which is usually unique to groups of individuals and religious affiliation factors have also been found to some extent to affect the rates of infant mortality. The type of marital union that closely relate to cultural and religious factors has also been found to have some effects in infant mortality in Kenya. For instance, Muslims have a higher infant mortality compared to Christians and the Nilotic tribes that have a higher infant mortality rate compared to the central Bantus.

\section{Conclusion and Recommendations}

\subsection{Conclusion}

As already pointed out the study sought to examine and compare the effects of the selected socio-economic, demographic, cultural and environmental factors on infant mortality in the high and low mortality regions in Kenya. Based on the finding of the study, the following conclusions can be made:-

a) The variable Mothers' occupation which was intended to capture the effects of resources available for child health care and hence a proxy for standard of living in the household. The results of this study support the premise that occupational categories associated with higher incomes lead to higher standard of living and thus relatively lower the risk of infant death. However, Mothers' occupation is only a significant determinant of infant in death in the low mortality region.

b) The mothers' education level was intended to capture knowledge level of childcare with the underlying assumption that the higher the level of education, the better the child care practices. The results of this study 
support the hypothesis "the risk of infant death varies with the level of education" However, Maternal education is only significantly associated with infant mortality in the high mortality region.

c) The results indicated that mothers' age at first birth is not significantly associated with infant death in both regions. However, preceding birth intervals were observed to significantly affect infant mortality in the high mortality region. It is further observed that shorter birth intervals increase the risk of infant death in the high mortality region. This concurs with theory, which holds that when birth intervals are short, the mother terminates breast feeding within a few months after birth, leading to poor child health.

d) Lastly religion and ethnicity were found to have no predictive effects on infant morality in both regions. However, the results of the logistic regression analysis indicate that religions differentials in infant mortality, albeit, of small magnitude, also exists in Kenya.

\subsection{Recommendations}

From the discussion above, it is clear that the main challenge facing the successful implementation of child survival programmes in the country is the existence of wide regional variations in infant mortality. In order to bridge the wide disparities existing among the various regions in the country with regard to infant death, the following recommendations are made:

Firstly, the results of the study indicate that maternal education is an important determinant of infant mortality in the high mortality region. It is, therefore, recommended that although the possibility of free primary education and free day secondary tuition has been realized in the country, the is need to implement wholly free education at secondary level for girls in the high mortality region. This will enable the future mothers to acquire knowledge as a basis for future career advancement and general empowerment.

Secondly, the potential for infant mortality reduction resulting from increased birth spacing in the high mortality region in Kenya is underscored by the study findings. There is thus an urgent need to formulate policies that could help increase the length of intervals between births. Additionally, since the findings of the study support the thesis that occupational categories associated with higher incomes lead to higher standards of living and thus lowering the risk of infant death, the government should implement favourable policies and programmes aimed at reducing the current poverty levels and enhancing women's financial and occupational status.

\section{Acknowledgement}

The comments on an earlier draft on which this paper is based by Prof. Z.B.Muganzi and Prof.L.D.E.Ikamari is gratefully acknowledged.

\section{References}

Misati, A. J. (2003) Determinants of Child Survival in Kenya: A comparative Study. Unpublished M.A. Thesis, P. S .R .I, University of Nairobi.

Misati, A, J (2011) Determinants of Child Survival in Kenya: A comparative Study Lambert Academic Publishing Gmbh.Saarbrucken, German.

Republic of Kenya (2002). National Development Plan (2002 - 2008): Effective Management for Sustainable Economic Growth and Poverty Reduction Government Printer, Nairobi.

Republic of Kenya (2000) National Population Policy of Sustainable Development. (Sessional Paper No. 1 of 2000). Ministry of National Planning, Nairobi.

Mosley W. H. and Chen, L. (1984). "An Analytical Framework for the Study of Child Survival in Developing Countries. "In Child Survival: Strategies for Research, Population and Development Review, Vol. 10 supplement, PP. 25 - 45, New York.

National Council for Population and Development (2009) Kenya Demographic and Health Survey (KDHS). Nairobi: Ministry of Planning \& National Development.

Ross, A. J., Mauldrin, W. P., Green, R. S. and Cooke, E. R. (1992) Family Planning and Child Survival Programmes as assessed in 1991. The Population council, New York .

Mott, F. L. (1982) Infant Mortality in Kenya. Evidence from the Kenya Fertility. Interventional Statistical Institute, Voorbug, Nertherlands

Hobcraft, J.N; McDonald.J.W and Rustein, S.O (1984) "Socio-economic factors in Infant and Child mortality: A cross - national comparison". Population studies. Vol 38 No.2. PP.193 - 223.

Ikamari, L. D. E. (1996) Factors Affecting Child Survival in Kenya. Unpublished PhD Thesis. Australian National University, Canberra

Muganzi, Z. S. (1990) Socio-cultural and Environmental Factors Affecting Infant and Child mortality in South Nyanza and Taita Taveta 
Districts. Unpublished IDRC Report, Nairobi

Mott, F. L. (1979) "Infant mortality in Kenya: Evidence from the Kenya Fertility Survey".Paper prepared at the Population Studies and Research Institute (PSRI) University of Nairobi, Nairobi.

Mott, F.L (1982) Infant mortality in Kenya. Evidence from the Kenya Fertility Survey.Vooburg.International Statistical Institute.

United Nations (1984) Mortality and health policy: A Measure for Development. New York.

United Nations (2003) Indicators for Monitoring the Millennium Development Goals, New York

Caldwell, J. C. (1979) "Education as a Factor of Mortality Rates" International Journal of Health Services Vol. 33. 1979.

Harrington, J (1974) "Economic development and mortality in infancy and childhood: comments from the West African case", Population Planning working paperNo.10.Ann Arbor, Department of population planning, school of Public Health.

Jain, A. K. (1985) Determinants of Regional Variation in Infant mortality in Rural India. Population Studies. London, Vol 39, No. 3 November, PP. $407-424$.

Teckle, B. and Shorter, F. C. (1985), "Determinants of Child Mortality: A Case Study Of Squatter Settlements in Jordan" in Child Survival: Strategies for research "W. H. Mosley and Linkolin Chen (Eds) Population and Development Review. N. Y. Vol. 10, Supplement, pp. $257-280$

Bicego, G. et al (1997). Sumve Survey on Adult and Childhood Mortality, Tanzania 1995.Macro International Inc. Calverton, Maryland, U.S.A

Khasakhala, A. A (1998) "Death Clustering in Families in Kenya.Implications for Child Survival and Maternal Health". Institute for Population Sciences. (Deemed University Denver, India. Unpublished PhD Thesis.

Kibet, M.K.I (1981) Differential Mortality in Kenya. Unpublished MSc Thesis, PSRI: University of Nairobi

K'oyugi, B. O. (1992) The Impact of Household and Community Environmental Factors on Infant and Child Mortality in Rural Kenya. Unpublished PhD Thesis, University of Nairobi.

Farah, A.A and Preston, S.H (1982) Child Mortality differentials in Sudan. Population and Development review. Vol.8.No.2, June, 1982.

Anker. A and Knowles (1977) "An empirical analysis of mortality differentials in Kenya at Macro and Micro levels". Population Paper No.60. Geneva: ILO. 